\title{
Desktop Video
}

National Cancer Institute

\section{Source}

National Cancer Institute. Desktop Video. NCI Thesaurus. Code C19542.

A videoconferencing system that can be used by an individual from a desktop computer.

A desktop conferencing system consists of a computer, an attached video camera,

microphone, and speakers, and a telephone or network connection. 